\title{
Prototyping AR EduGame for children: learning Indonesian culture
}

\author{
Endah Sudarmilah ${ }^{1, *}$, Heru Supriyono ${ }^{1,2}$, Umi Fadlilah $^{1,2}$, Fatah Yasin Al Irsyadi ${ }^{1}$, and Azizah Fatmawati ${ }^{1}$ \\ ${ }^{1}$ Universitas Muhammadiyah Surakarta (UMS), Informatics Department, Faculty of Communication and Informatics, Surakarta, \\ Indonesia \\ ${ }^{2}$ Universitas Muhammadiyah Surakarta (UMS), Electrical Engineering, Faculty of Engineering, Surakarta, Indonesia
}

\begin{abstract}
Learning Indonesian culture is a part of the curriculum for elementary school students. However, it faces a challenge of the decreased interest of reading textbooks. It can be solved by using a 3D animation that is loved by the children. Therefore, this study aimed to design a prototype of augmented reality (AR) EduGame (Educational Game) as a learning media of Indonesian culture for the children. This study used research and development method for an AR application, and then its system was tested on black box testing. The AR EduGame prototype and its testing results are run appropriately, system testing show that every button and transition for both AR EduGame applications, traditional dance and gamelan. Morover, it can be implemented by elementary school children.
\end{abstract}

\section{Introduction}

Digital game is used not only for entertainment nowadays. In recent years, serious games are growing rapidly [1], particularly for education, simulation, medical research, and therapy [2].

Recent game application frequently used augmented reality (AR) technology [3]. The AR system can be defined as an application that augments real and virtual objects in the same space, which will interact in realtime [4]. The process of augmenting virtual and realworld data can give the user access to multimedia contents [5].

In education, the decreased interest of reading textbooks in elementary school students is one of the challenges nowadays. The use of two-dimension (2D) images in the book to make it interesting for the students is not an optimal solution. The static images in the book tend to make students passive and having less interaction during learning because the images do not provide feedback response, seem unreal, and they are less attractive for the students.

Meanwhile, entertainment technology continues to present more interesting and interactive contents such as in 3D-animation or movies. Augmented reality has a potential to replace the internet in terms of size and application. The implementation of this technology in education domain does not necessarily guarantee success. However, the lack of new technology implementation relates to the low learning achievement [5].

Students tend to learn art and culture seriously only before the exam. Improving student interest in learning requires a more entertaining learning media [6]. The AR technology can be used to introduce arts and culture interactively and in a more interesting way. Therefore, the implementation of AR technology could become an effective solution for teaching Indonesian culture for the students. Using AR technology to improve student critical thinking is one challenge faced by the teachers. Therefore, this study aimed to develop AR technology named EduGame as a learning media of Indonesian culture for elementary school students.

One study concerning computer games is conducted by [7], where they observe the users interact with the visual display using various input devices, such as a joystick, gamepad, steering wheel, or game console. Computer games originally made for fun and entertainment. However, they are developed into providing more beneficial aspects for the users, which are called serious games.

Serious games not only focus on entertainment but also learning to embed knowledge into the gaming experience. One study regarding serious game for application in company training, education, health, public policy, and other strategic objectives is conducted by [8]. In other studies, the serious game also implemented in health [9], health information [10], and education [11].

Education game studied by Ronimus focus more on children [12]. It is an online game named GraphoGame. A design is used to assess the effect of challenge level and reward system. Children involvement is assessed by session frequency and duration. Meanwhile, Hou and $\mathrm{Li}$ evaluate several aspects of an adventure game titled Boom Room [13], such as learning effectiveness, game acceptance, and game flow experience. This game is designed and developed to teach the knowledge of

\footnotetext{
* Corresponding author: Endah.Sudarmilah@ums.ac.id
} 
computer assembly. Samples are asked to finish pre-test and post-test. The students not only evaluate benefit, ease of use, and design element of the game, they also assess their experience in various game flow dimension. Moreover, games can also be conducted to stimulate the intelligence of children [14,15] which in design using anthrophomorphic character that is believed to be suitable for child development [16].

Augmented reality (AR) technology is defined as a device situated in 'Reality-Virtuality Continuum' between real and virtual worlds [3]. $\mathrm{AR}$ is an implementation of digital content in the real world, while on the contrary, augmented virtuality is a concept of transplanting real-world content to the virtual world, as illustrated in Figure 1. Hence, augmented reality can be used as a channel to integrate learning in both virtual and real worlds [5].

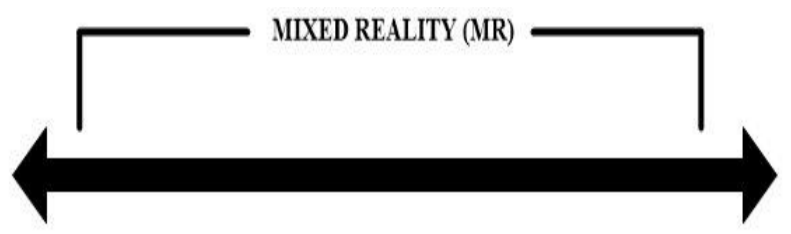

$\begin{array}{cccc}\text { REAL } & \text { AUGMENTED } & \text { AUGMENTED } & \text { VIRTUAL } \\ \text { ENVIRONMENT } & \text { REALITY (AR) } & \text { VIRTUALITY (AV) } & \text { ENVIRONMENT }\end{array}$

Fig. 1. Augmented Reality (AR) Technology Position.

\section{Method}

This study aimed to design augmented reality application, EduGame, as a learning media for elementary school students. This was a research and development study based on software development process using SDLC (software development life cycle) method with modified Waterfall model [17,18]. The method is displayed in Figure 2.

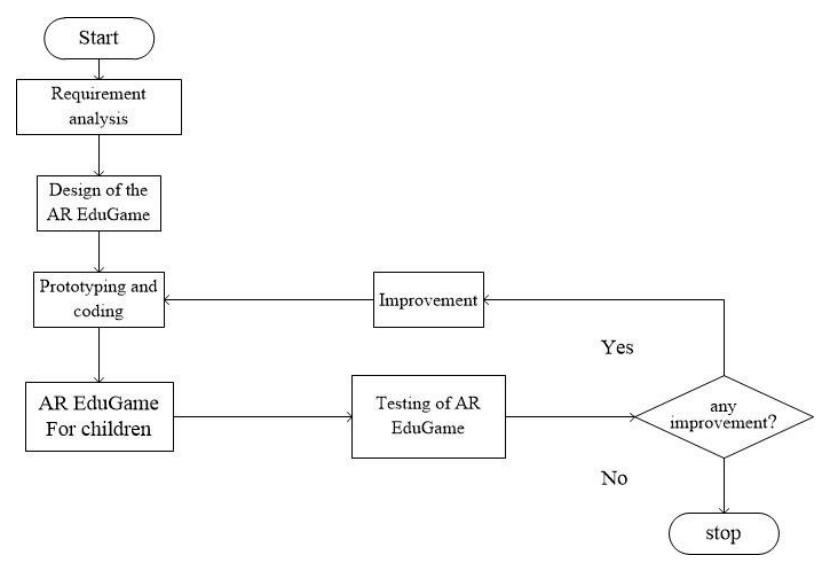

Fig. 2. Research Method.

As can be seen in Figure 2, research steps for each year are explained in detail in the following subsection.

\subsection{Requirement analysis}

In this step, we analyzed required information for augmented reality game contents based on 2013 Indonesian elementary school curriculum, appropriate reference textbooks, and suitable game development technology for the application.

\subsection{Design of the AR EduGame}

In this step, we generated data flow and storyboard of the game.

\subsection{Prototyping and coding}

In this step, the application prototype was built using augmented reality game programming based on requirement analysis and generated storyboard adjusted with elementary school learning system. For example, as stated by Vygotsky, the increased number of stimulus will encourage the intensity of thinking; thus, a person will be able to do something according to his capacity (scaffolding). This was accommodated when designing difficulty levels of the game [19]. The process of prototyping the software was conducted in the laboratory using the appropriate instruments.

\subsection{Testing of AR EduGame}

After the prototyping step, the application was validated using system testing in the laboratory (black box testing) with varied system conditions to assess the feasibility of the system.

\subsection{Improvement}

Based on feedback in the form of expert judgment from elementary school teachers, we improved the prototype of the game.

\section{Results and Discussion}

\subsection{AR EduGame for Indonesian culture learning}

The results of AR EduGame was started from application design using UML (unified modelling language) modelling, which is a standardized programming language for designing and documenting software, particularly the one with Use Case model [20].

The use case is a coherent functionality unit expressed as transactions between actors and the system. The use case of the proposed application is shown in Figure 3, while the description is presented in Table 1.

Based on the design of AR EduGame application, we conducted storyboarding to generate two AR EduGame applications [21] for traditional dance and gamelan learning, which are indigenous to Indonesia. The screenshot of AR EduGame user interface is shown in Figure 4. 


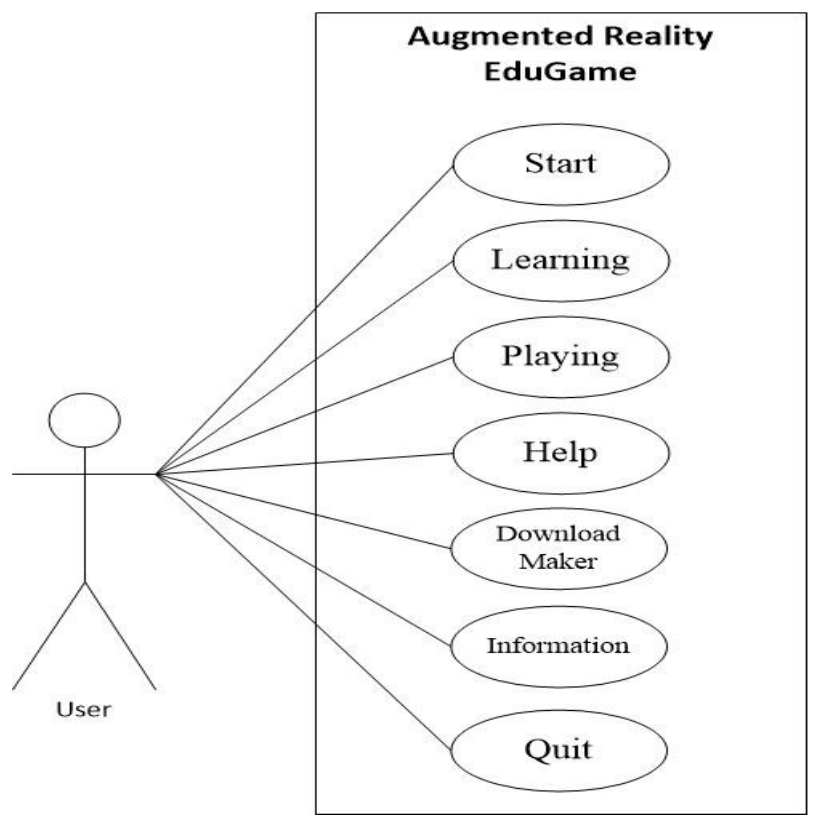

Fig. 3. Use case of AR EduGame.

Table 1. Use Case Definitions of AR Edugame.

\begin{tabular}{|c|l|l|}
\hline No & \multicolumn{1}{|c|}{$\begin{array}{c}\text { Use Case } \\
\text { Element }\end{array}$} & \multicolumn{1}{|c|}{ Description } \\
\hline 1 & Start & $\begin{array}{l}\text { Contains notification to exit the } \\
\text { application }\end{array}$ \\
\hline 2 & Learning & $\begin{array}{l}\text { Learning menu presented in } \\
\text { augmented reality }\end{array}$ \\
\hline 3 & Playing & $\begin{array}{l}\text { Playing the augmented reality } \\
\text { game with guided material based } \\
\text { on elementary school } \\
\text { curriculum, including quizzes }\end{array}$ \\
\hline 5 & Help & $\begin{array}{l}\text { Comprised of explanation of the } \\
\text { application and instructions of } \\
\text { how to use it. }\end{array}$ \\
\hline 5 & $\begin{array}{l}\text { Download } \\
\text { Marker }\end{array}$ & $\begin{array}{l}\text { Contains link to download } \\
\text { marker }\end{array}$ \\
\hline 7 & Quit & $\begin{array}{l}\text { Contains information relating to } \\
\text { application developer }\end{array}$ \\
\hline
\end{tabular}

\subsection{Testing AR EduGame}

Before it was presented to the children, the AR AR EduGame application was tested using black box testing. The test aimed to assess whether the game runs appropriately, including each interface and button works according to the design and whether the improvements satisfied the teachers. The black box testing [14] [18] was conducted for both AR EduGame applications, traditional dance and gamelan. The results show that every button and transition of the system in each page run appropriately. The results of black box testing of both applications are presented in detail in Table 2 .
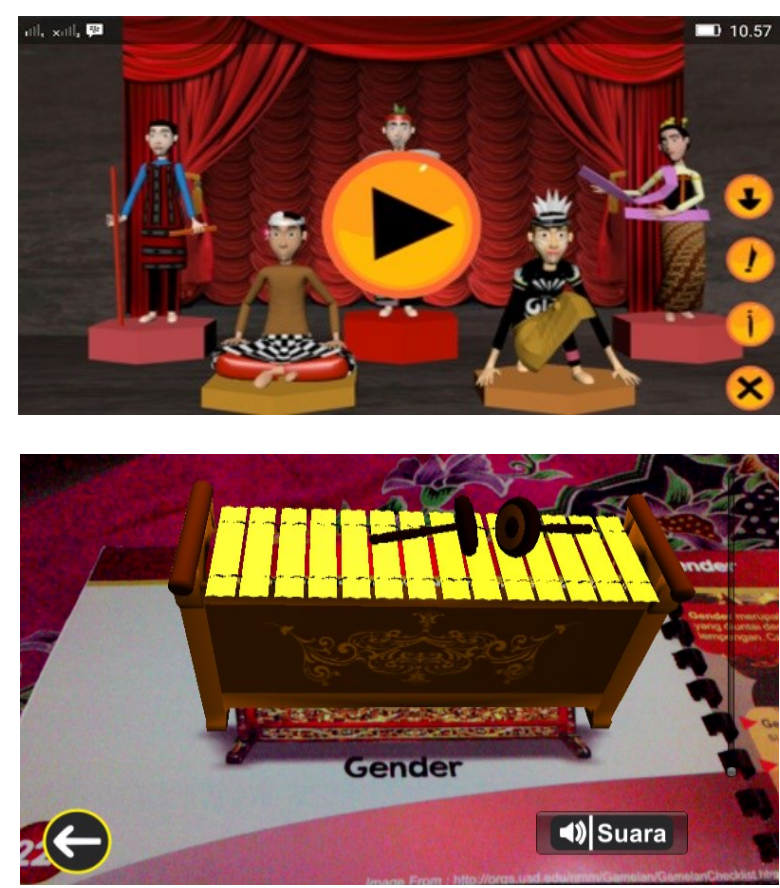

Fig. 4. Example of AR EduGame Screenshot.

Table 2. Black Box Testing Results.

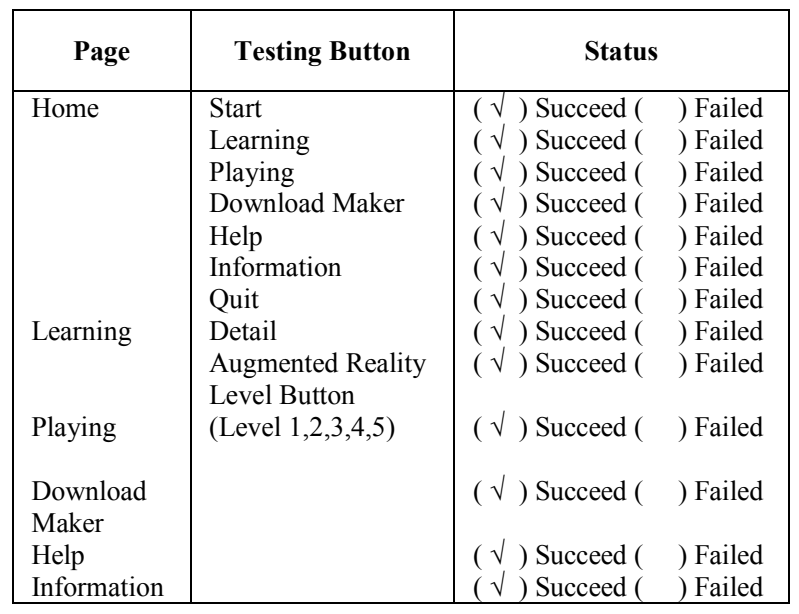

\section{Conclusion and Future Works}

The results show that AR EduGame prototype could be used as a learning media for elementary school students in learning Indonesian culture. The results of system testing show that every button and transition of the system for both AR EduGame applications, traditional dance and gamelan, run appropriately. These applications will be implemented by elementary school children as future works.

This work was supported by Informatics Department, Faculty of Communication and Informatics of Universitas Muhammadiyah Surakarta (UMS). 


\section{References}

1. A. Szczesna, J. Grudzinski, T. Grudzinski, R. Mikuszewski, A. Debowski, IEEE 1st Int. Conf on $\mathrm{SeGAH,} \mathrm{(2011)}$

2. K. Schreiner, IEEE Comput. Graph. Appl., 28, 1217, (2008)

3. R. Azuma, A Survey of Augmented Reality (1997)

4. R. Azuma, Y. Baillot, R. Behringer, S. Feiner, S. Julier, B. MacIntyre, IEEE Comput. Graph. Appl., 21, 34-47, (2001)

5. M. Bower, C. Howe, N. McCredie, A. Robinson, D. Grover, IEEE 63rd An. Conf. ICEM, (2013)

6. V. Vorsen, J. Susanto, C. Gunawan, Aplikasi Perangkat Ajar Pengenalan Seni dan Budaya Indonesia 'Petualangan Sibi' untuk Sekolah Dasar Kelas VI, (2013)

7. B. Bowman, N. Elmqvist, T. J. Jankun-Kelly, IEEE Trans. Vis. Comput. Graph., 18, 1956-1968, (2012)

8. M. Zyda, Computer (Long. Beach. Calif), 38, 2532, (2005)

9. G. P. Tolentino, C. Battaglini, A. C. V. Pereira, R. J. de Oliveria, M. G. M. de Paula, Third Int. Conf. on GVW for Serious App., (2011)

10. A. Elmaghraby, A. Mendez, B. G. Zapirain, W. Sheta, S. el Shehaby, 17th Int. Conf. on CGAMES, (2012)

11. C. S. Longstreet, K. L. Cooper, CSEE\&T, (2011)

12. M. Ronimus, J. Kujala, A. Tolvanen, H. Lyytinen, Comput. Educ., 71, 237-246, (2014)

13. H.-T. Hou, M.-C. Li, Comput. Human Behav., 30, 29-38, (2014)

14. E. Sudarmilah, A. Susanto, R. Ferdiana, N. Ramdhani, Int. Conf. on Appl. Sys.Innov. (ICASI), (2017)

15. E. Sudarmilah, U. Fadlilah, A. Susanto, R. Ferdiana, N. Ramdhani, P. I. Santosa, Int. J. Pure Appl. Math., 118, 539-544, (2018)

16. E. Sudarmilah, A. Susanto, R. Ferdiana, N. Ramdhani, Int. J. Multimed. Ubiquitous Eng., 12, 37-44, (2017)

17. A. M. Langer, Guide to Software Development: Designing and Managing the Life Cycle. Springer, (2012)

18. A.A.Puntambekar, Software Engineering, (2009)

19. J. Santrock, S. R. Yussen, Child Development, (2011)

20. M. D. S. Soares, J. Vrancken, A. Verbraeck, J. Syst. Softw., 84, 328-339, (2011)

21. R. Khaled, A. Vasalou, Int. J. Child-Computer Interact., 2, 93-100, (2014) 